\title{
Laparoscopic bile duct exploration seems to be safe in higher-risk patients compared to endoscopic sphincterotomy and subsequent laparoscopic cholecystectomy, in a high-volume centre
}

\author{
H. Noble $\cdot$ E. Whitley $\cdot$ S. Norton $\cdot$ M. Thompson
}

Received: 8 December 2010/Accepted: 22 December 2010/Published online: 7 February 2011

(C) Springer Science+Business Media, LLC 2011

We thank the authors [1] for their comments regarding our study [2]. We have indeed gone some way to show that bile duct exploration appears to be as safe as and more efficient than the two-stage alternative approach of endoscopic sphincterotomy followed by laparoscopic cholecystectomy in higher-risk patients fit enough to undergo surgery [3]. However, we recently presented some data at the AUGIS annual meeting that does suggest that there is a more profound reduction in postoperative pulmonary function in higher-risk patients following laparoscopic bile duct exploration than after laparoscopic cholecystectomy alone [4]. One might conclude, therefore, that higher-risk patients with significant lung disease might best be treated by sphincterotomy.

With regard to the "learning curve" period, it was not our intention to state a number to reach to gain competence in the procedure. In our study, this period encompassed the first 5 years of the series during which the technique was refined as described in the article. Regrettably, accurate data regarding operation times were not collected prospectively so this factor was not investigated. We estimate that with all the necessary equipment available, a surgeon with advanced laparoscopic skills might need to perform approximately 50 procedures to be comfortable with the

H. Noble $\cdot$ S. Norton $\cdot$ M. Thompson

Department of Surgery, Southmead Hospital,

Bristol BS10 5NB, UK

E. Whitley

Department of Social Medicine, University of Bristol,

Bristol BS8 2PR, UK

H. Noble $(\bowtie)$

Derriford Hospital, Plymouth Hospitals NHS Trust,

Plymouth PL6 8DH, UK

e-mail: hamish.noble@nhs.net technique, but this figure would be influenced by previous experience with open bile exploration.

A controlled bile leak following choledochotomy in a number of patients is inevitable. This is probably due to a combination of factors: the latent tone of the biliary sphincter, the quality of the closure of the choledochotomy, and small fragments of stones or blood clots within the duct that pass spontaneously in the first few postoperative days causing temporary obstruction. We take great care not to instrument the ampulla and thus avoid any episodes of procedure-related pancreatitis, and we would agree that any instrumentation of the ampulla would increase the risk of a bile leak. We are aware of some surgeon's practice of administering hyoscine$\mathrm{N}$-butylbromide in the postoperative period to relax the sphincter but there is no evidence to suggest its efficacy.

Disclosures H. Noble, E. Whitley, S. Norton, and M. Thompson have no conflicts of interest or financial ties to disclose.

\section{References}

1. Kilambi R, Bansal VK, Misra MC (2010) A study of preoperative factors associated with a poor outcome following laparoscopic bile duct exploration. Surg Endosc. doi:10.1007/s00464-010-1438-7

2. Noble H, Whitley E, Norton S, Thompson M (2011) A study of preoperative factors associated with a poor outcome following laparoscopic bile duct exploration. Surg Endosc 25:130-139

3. Noble H, Tranter S, Chesworth T, Norton S, Thompson M (2009) A randomised, clinical trial to compare endoscopic sphincterotomy and subsequent laparoscopic cholecystectomy with primary laparoscopic bile duct exploration during cholecystectomy in higher risk patients with choledocholithiasis. J Laparoendosc Adv Surg Tech A 19(6):713-720

4. Noble H, Barry J, Skyrme-Jones A, Norton SA, Thompson MH (2010) The cardio-pulmonary and inflammatory effects of laparoscopic and endoscopic treatment of bile duct stones in higher risk patients. BJS 97(5):42-43 